\title{
The influence of the percentage of porosity on the Thermal conductivity of a composite material, for example clay
}

\author{
ABDELKRIM MOUFAKKIR ${ }^{1 *}$, ABDERRAHIM SAMAOUALI ${ }^{1}$, ABDELLAH ELBOUZIDI $^{1}$, \\ SALAH EL ALAMI ${ }^{2}$, ABDERRAHIM DINANE ${ }^{3}$
}
${ }^{1}$ Team Thermodynamic-Energy, Energy Research Center, Department of Physics, Faculty of Sciences, Mohammed V University, B.P. 1014, in Rabat, 10090, MOROCCO
${ }^{2}$ Laboratory of Condensed Matter and Interdisciplinary Sciences, Faculty of Sciences, Mohammed V University in Rabat, 4 Avenue Ibn Battouta B.P. 1014 RP, MOROCCO
${ }^{3}$ Royal Naval School, Department of Research and Projects, Laboratory of Thermodynamics, Boulevard Sour Jdid, Casablanca 20000, MOROCCO

\begin{abstract}
The purpose of this work is to study the influence of the percentage of porosity, that is to say the volume of air compared to total volume on the thermal conductivity of clay at different degrees of temperature, this study is very interesting because clay is used in several fields for example construction, pottery, etc, and also in certain regions of the world as a building material and especially in countries which at a higher temperature, for this we perform together experiments on a mass of clay with a cubic shape of dimensions $(10 \mathrm{~cm} * 10 \mathrm{~cm} * 10 \mathrm{~cm})$, but with each experiment we varied the percentage of porosity, then we relied on the CT-METRE device to measure the thermal conductivity.
\end{abstract}

Key-Words: - Clay, Porosity, Temperature, Thermal Conductivity.

Received: May 18, 2019. Revised: June 26, 2020. Accepted: June 29 2020. Published: June 30, 2020.

\section{Introduction}

The term clay comes from the Greek word "argilos", whose root argos means white, they are aluminosilicates whose structure is formed by a stack of sheets [1]. Clay is a material of sedimentary rock, often composed of minerals $\mathrm{AL}_{2} \mathrm{O}_{3}$ [2], used by man since the most ancient and necessary for daily life, which we find in nature in different colors, composed of red and yellow [3][4]. Clay is considered to be the oldest building material, and until now it is the most widely used in the world, it is natural, durable and less expensive [5-8]. Clay can be used in several fields, for example as a building material. In the form of clay bricks, also in the pottery sector, also in the field of monument restoration, unlike new modern building materials [9], clay naturally preserves half of the old wood. Its use saves time and cost, protects us from heat peaks as well as cold nails [10], it allows to store a large part of the energy and energy efficiency, while the study of thermal insulation plays a very important role so we are adding other works. In this work consists in studying the effect of the porosity ratio on the thermal conductivity at different temperature degrees of the state of a clay composite material in this material capable of adding more value to the clay properties that we have shown at starting from the experimental results by means of a "CT-Metre" apparatus. We conclude that the thermal conductivity decreases with increasing porosity so we can choose a material with reliable mechanical characteristics and we take into account the percentage of porosity depending on the region in which we want to make our construction [11-13]. (Clay Prepared taken from Oulja Sale)

\section{Experimental protocol}

We prepare five pairs clay samples of cubic shape of dimensions $(10 \mathrm{~cm} * 10 \mathrm{~cm} * 10 \mathrm{~cm})$ [3] by a mold then we leave a sample as it is, and we build others in such a way that the porosity represented $5 \%$ for the second, and the others $10 \%, 20 \%, 30 \%$. Then we put them in the oven at $40{ }^{\circ} \mathrm{C}$ for 72 hours, to eliminate the amount of water that existed when the samples wet [14][15][4]. Then we do the following procedure we measure the thermal conductivity for 
each sample in different temperature $(\mathrm{T}=293 \mathrm{~K}$, $303 \mathrm{~K}, 313 \mathrm{~K}, 323 \mathrm{~K})$. Some relevant studies can be found in [16],[17] and [18].

\subsection{Presentation of the assembly}

The thermal conductivity of a material is measured by measuring the conductivity using a "CT-Metre" (Figure 1) equipped with accessories such as sondes (Figure 3) for solids, A glove box composed a thermocouple used to stabilize the temperature and an interface which assembles the assembly with a computer in order to display and process the measured digital values. Again, CT METRE, an easy-to-carry device, was developed to facilitate an accurate assessment of the thermal properties of a number of materials, such as bricks, rocks, earth and aerated concrete. Bitumen, pulverized materials, resins or complex products [3].

\subsection{Description of the CT-Metre}

The CT-Metre consists of two phases, firstly the control unit, responsible for generating the heating power and analyzing the temperature rise graph induced in the material to be tested. And secondly by the sonde is busy allocating the power. Heating and to capture the induced temperature [3].

Connect the ring sonde (Figure 3.) to the plug connected to the "CT-Metre" device and then insert it between two samples of the same size and shape so that it scans the sample in volume. After pressing the button that exists on the device after it displays the results on software that already install on the computer.

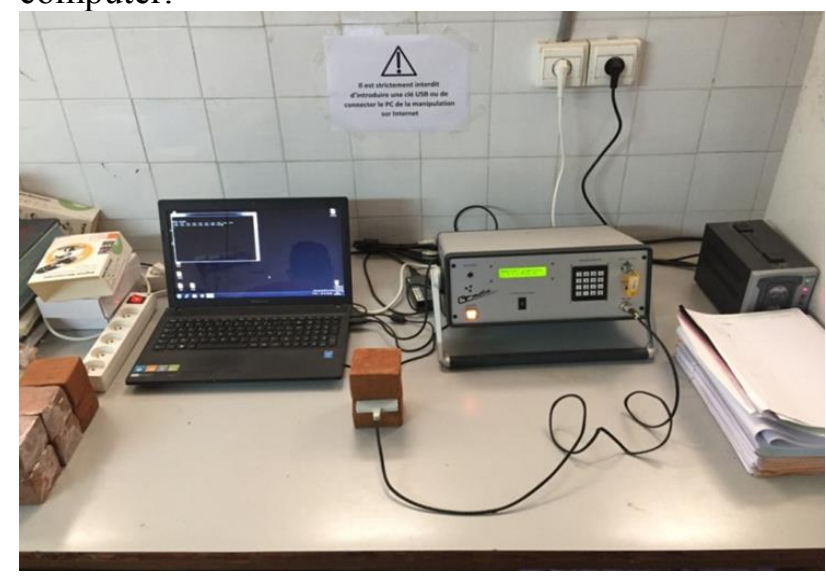

Figure 1. General diagram of the "CT-Metre"

These five samples were studied in cubic forms, each sample is divided into two, heat treatment is then carried out in the oven at $40{ }^{\circ} \mathrm{C}$ for 72 hours for the reason of reducing the water and finally or overloading the material. (Figure 2.)

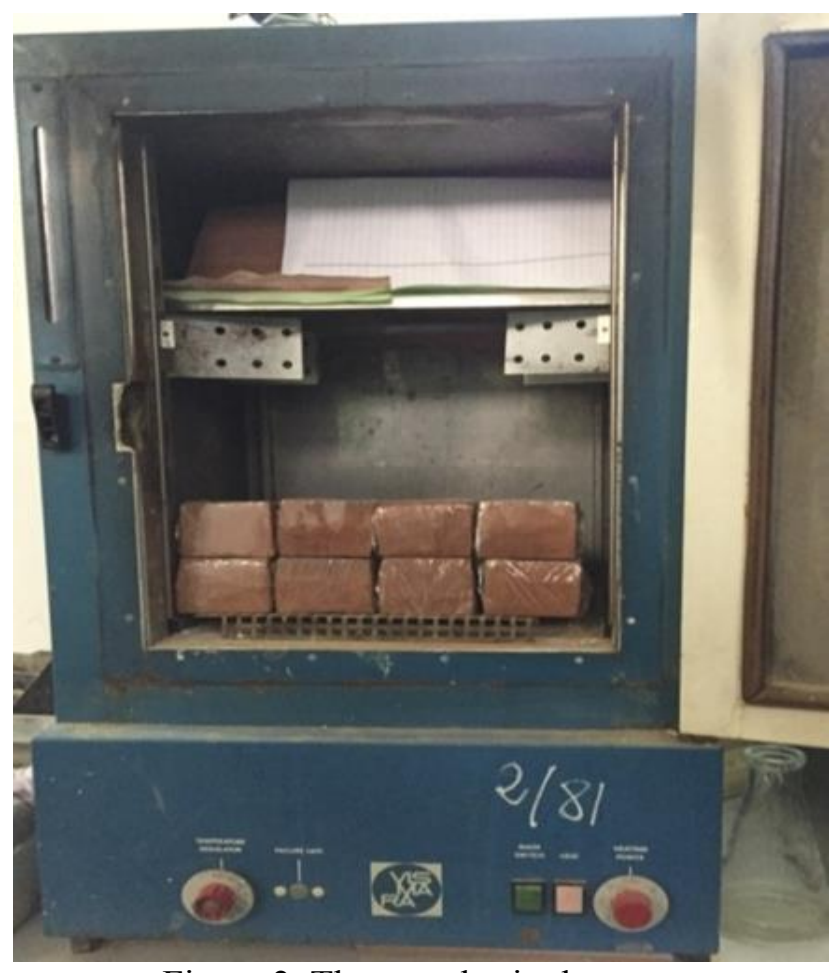

Figure 2. The samples in the oven

The ring sonde consists of a flexible printed circle with a thickness of $0.2 \mathrm{~mm}$ and dimensions $60 * 90 \mathrm{~mm}$, intended to be inserted between two flat parts of the sample to be measured.

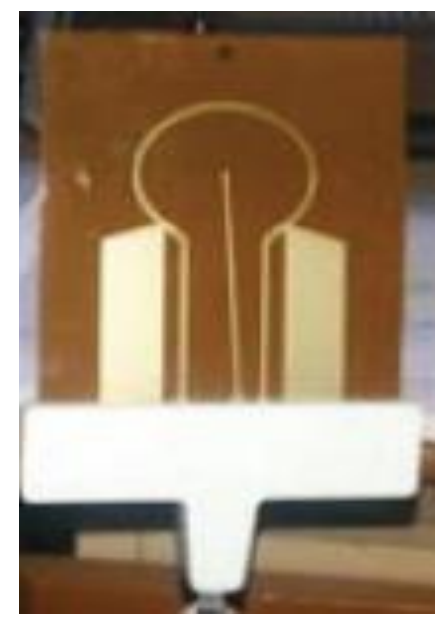

Figure 3. The Ring sonde

The glove box its role is the conversation of the temperature changes of a sample, the latter composed of three bodies linked to each other and each giving their function is as follows: a contact thermometer which adjusts the requested temperature, bulbs in flames during launch of the sample in the glove box to heat the sample and then a fan which brews the heat in the latter (Figure 4) [3]. 


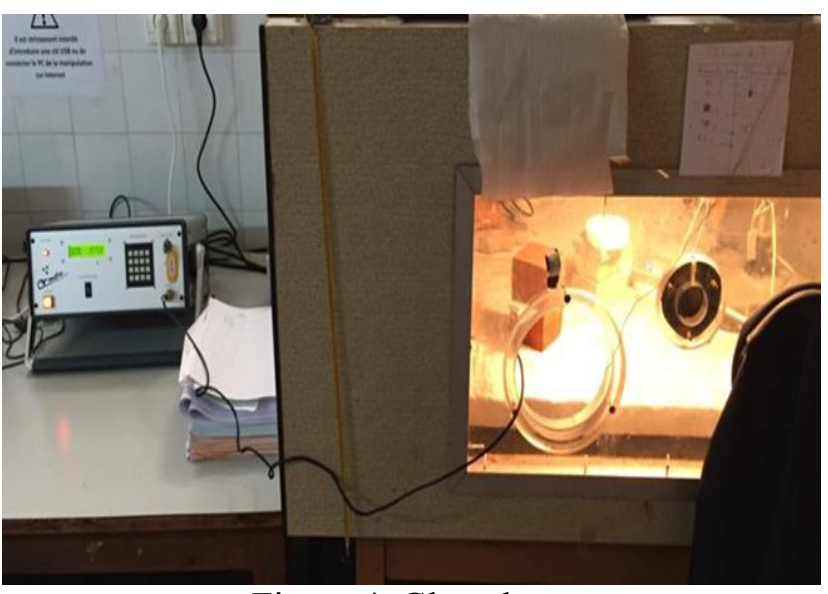

Figure 4. Glove box

The following table illustrates the mechanical and electrical characteristics of the CT-Metre device (Table 1).

\begin{tabular}{|c|c|}
\hline Characteristics & Values \\
\hline $\begin{array}{c}\text { power delivered for the } \\
\text { ring sonde (w) }\end{array}$ & From 0 to 2,5 \\
\hline heating time (s) & 400 \\
\hline measure time (s) & 500 \\
\hline Resistance (ohm) & 2,5 \\
\hline Cabinet size (mm) & $400 \times 145 \times 260$ \\
\hline Box weight (Kg) & 8 \\
\hline Power supply & $230 \mathrm{Vac} / 50-60 \mathrm{~Hz}$ \\
\hline
\end{tabular}

Table 1. Mechanical and electrical characteristics of the CT-Metre device [3]

\section{Variation of thermal conductivity as a function of porosity for different temperature values}

After measuring the samples on the CT-Metre, we obtain the following experimental results (Table 2.)

\begin{tabular}{|l|ll|ll|ll|ll|}
\hline$x_{\text {air }}$ & $\boldsymbol{\lambda}$ & at & $\boldsymbol{\lambda}$ & at & $\boldsymbol{\lambda}$ & at & $\boldsymbol{\lambda}$ & at \\
\hline
\end{tabular}

\begin{tabular}{|c|l|l|l|l|}
\hline$(\%)$ & $\begin{array}{l}(\mathrm{T}=293 \\
\mathrm{K})\end{array}$ & $\begin{array}{l}(\mathrm{T}=303 \\
\mathrm{K})\end{array}$ & $\begin{array}{l}(\mathrm{T}=313 \\
\mathrm{K})\end{array}$ & $\begin{array}{l}(\mathrm{T}=323 \mathrm{~K} \\
)\end{array}$ \\
\hline 0 & 0,785 & 0,741 & 0,715 & 0,701 \\
\hline 5 & 0,721 & 0,704 & 0,665 & 0,641 \\
\hline 10 & 0,685 & 0,666 & 0,645 & 0,630 \\
\hline 20 & 0,565 & 0,540 & 0,512 & 0,486 \\
\hline 30 & 0,487 & 0,420 & 0,390 & 0,357 \\
\hline
\end{tabular}

Table 2. Experimental measurements of thermal conductivity as a function of porosity at different temperature values

And from table 2 we can plot each percentage of porosity as a function of temperature we obtain the following curves, this curves is represented the change in porosity on the thermal conductivity at different temperature values (Figure 5).

(a)

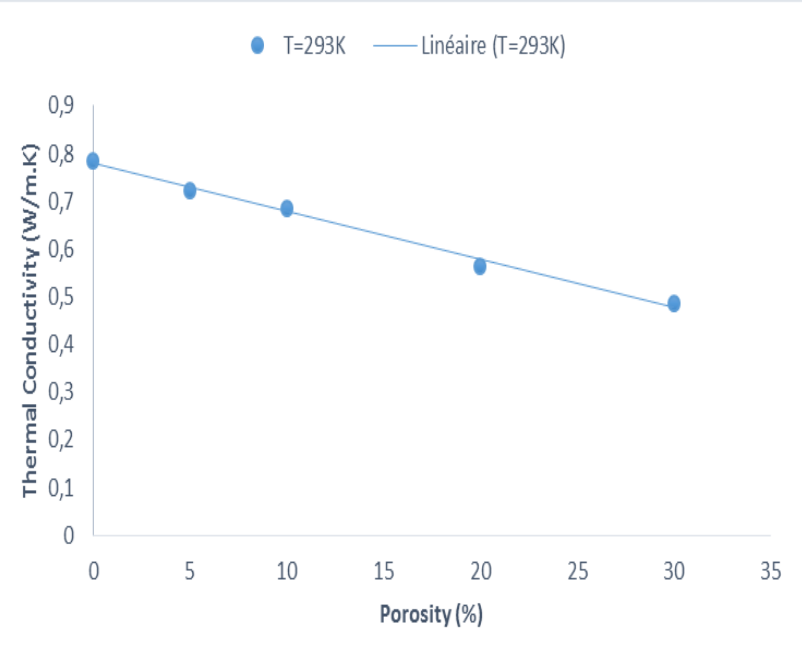




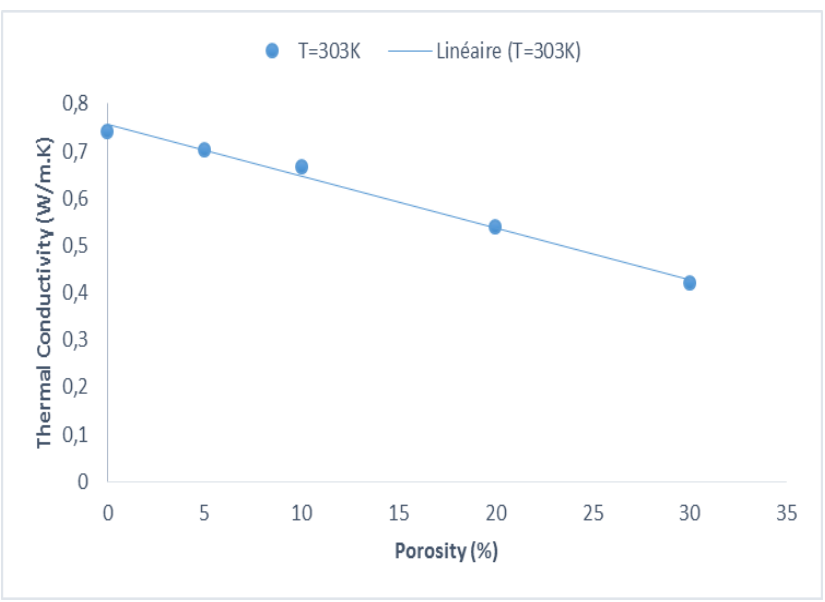

(c)

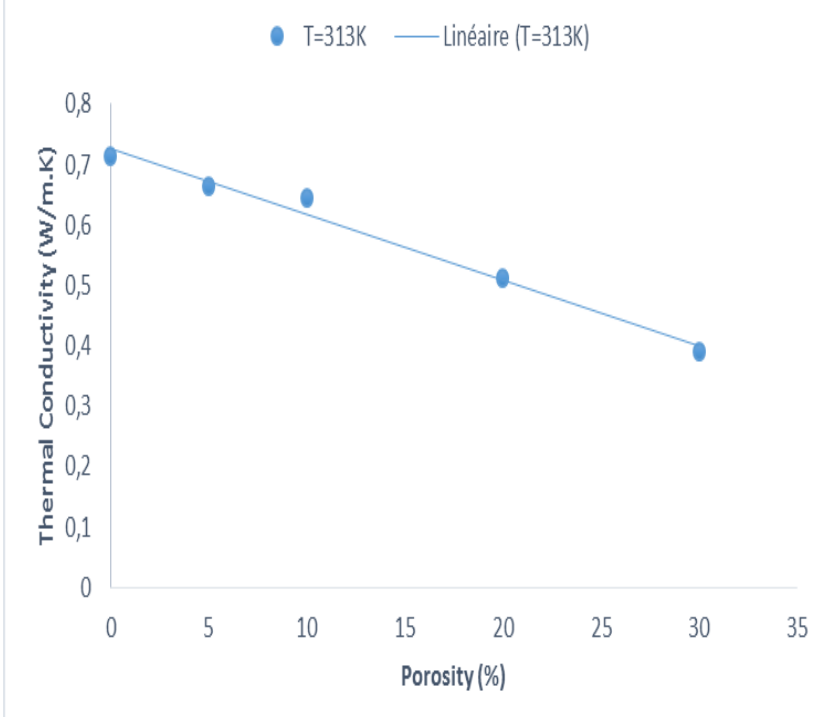

(d)

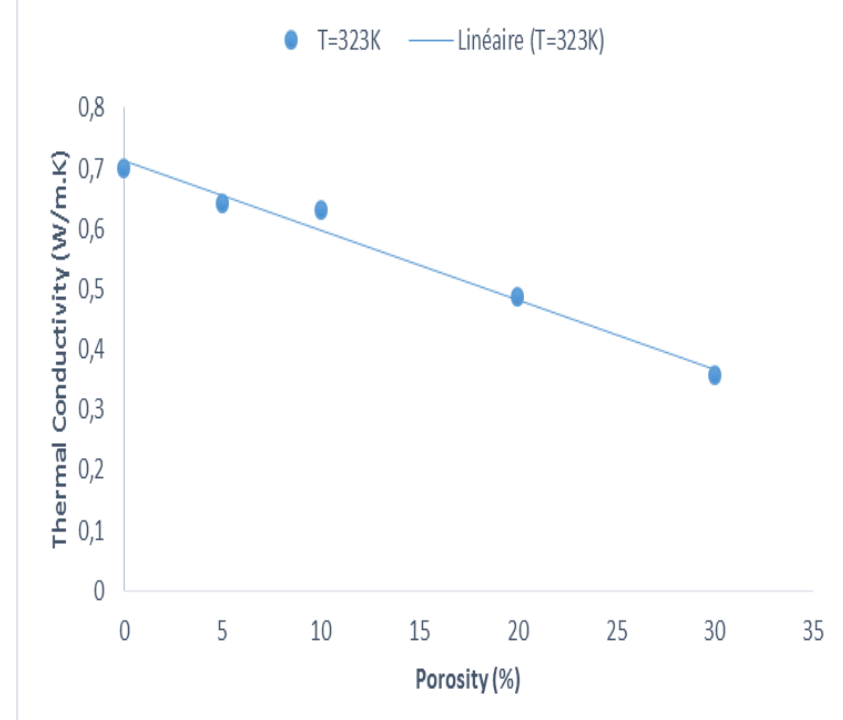

(e)

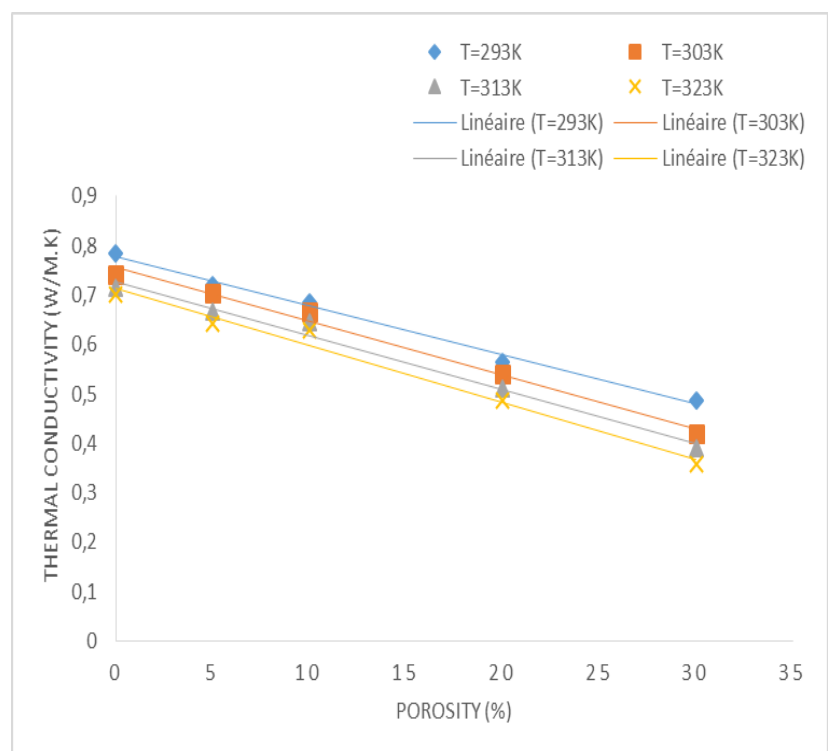

Figure 5. (a, b, c, d, e) Influence of thermal conductivity on porosity at different temperatures successively (293K, 303K, 313K, 323K and all temperature)

In general, we find that the thermal conductivity decreases with the increase in the porosity percentage in each material, for the first sample when the porosity was $0 \%$ the thermal conductivity is $0.785 \mathrm{~W} \cdot \mathrm{m}^{-1} \cdot \mathrm{K}^{-1}$ at temperature $\mathrm{T}=293 \mathrm{~K}$ and decreases until reaching $0.701 \quad \mathrm{~W} \cdot \mathrm{m}^{-1} \cdot \mathrm{K}^{-1}$ at temperature $\mathrm{T}=323 \mathrm{~K}$, and for the percentage sample $5 \%$ the thermal conductivity is $0,721 \mathrm{~W} \cdot \mathrm{m}^{-}$ ${ }^{1} \cdot \mathrm{K}^{-1}$ at temperature $\mathrm{T}=293 \mathrm{~K}$ and decreases until reaching $0.641 \mathrm{~W} \mathrm{~W} \cdot \mathrm{m}^{-1} \cdot \mathrm{K}^{-1}$ at temperature $\mathrm{T}=323$ $\mathrm{K}$, we observe the thermal conductivity value decreases from sample to sample at the same temperature, this decrease aggravated with the percentage increase in porosity and becomes 0.487 $\mathrm{W} \cdot \mathrm{m}^{-1} \cdot \mathrm{K}^{-1}$ at temperature $\mathrm{T}=293 \mathrm{~K}$ for the sample of $30 \%$.

We can interpret these results by the fact that the thermal conductivity decreases with the increase in air which contains the sample therefore the thermal conductivity is inversely proportional with the quantity of air which exists in the pores.

\section{Variation of thermal conductivity as a function of temperature for different values of porosity}

After having measured the samples on the CTMetre, we obtain the following experimental results in Table 2. And from these measurements, we can also conclude the influence of thermal conductivity 
as a function of temperature for different porosity values, we can plot these curves (Figure 6), which represent the change in thermal conductivity versus temperature at different percentage of porosity $(0 \%$, $5 \%, 10 \%, 20 \%$, and $30 \%$ ).

(a)

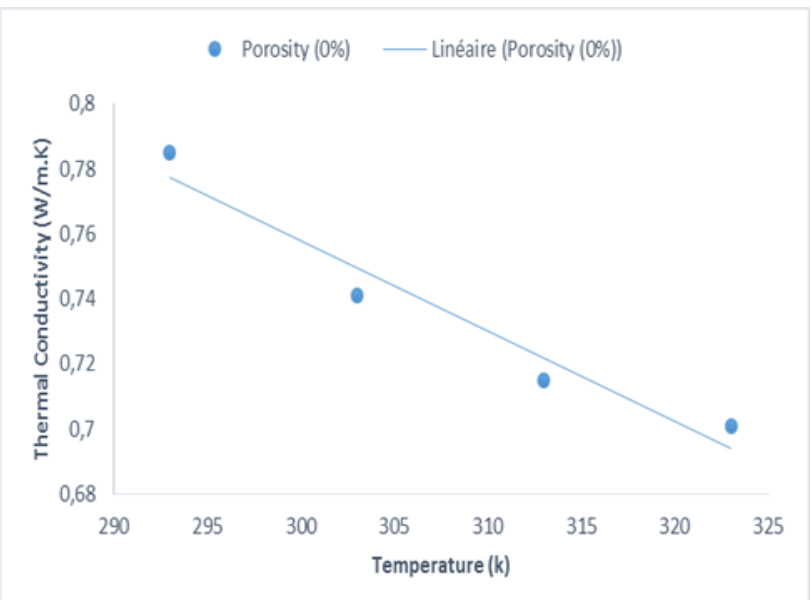

(b)

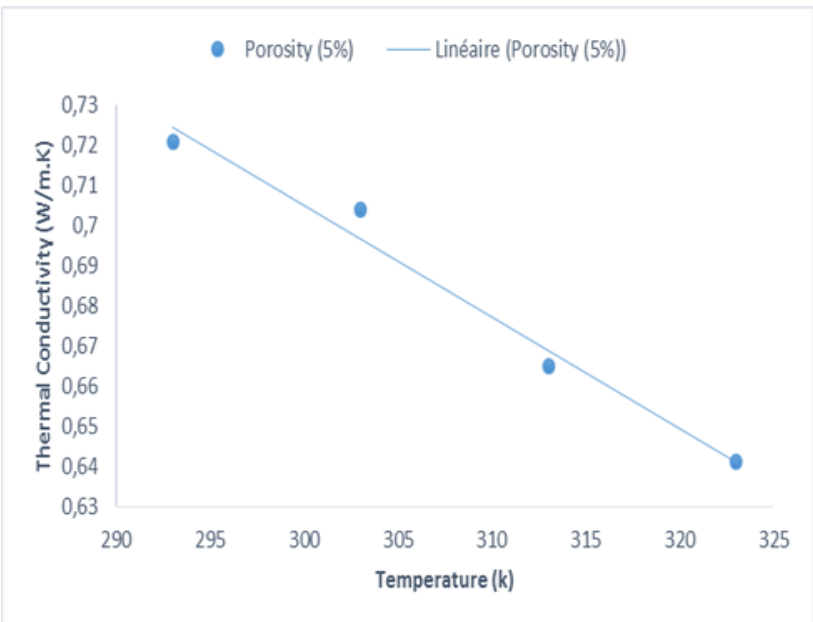

(c)

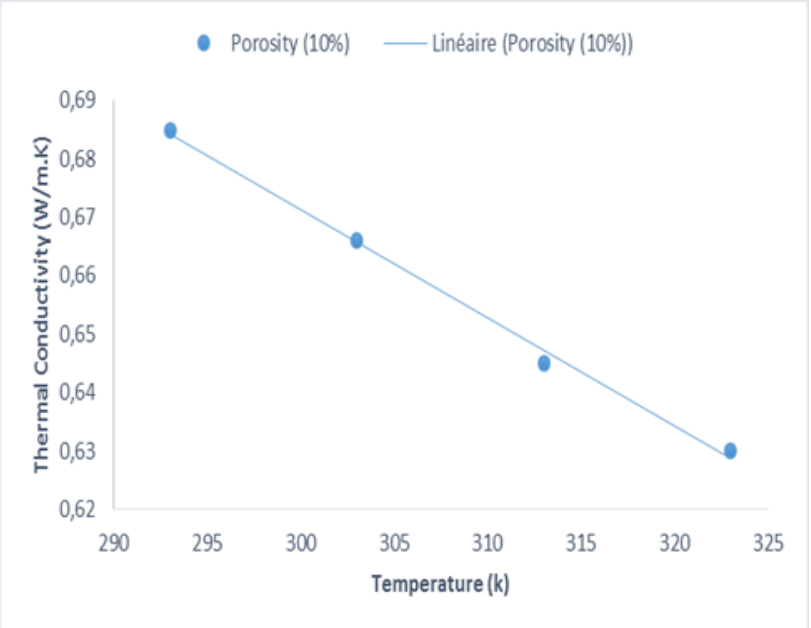

(d)

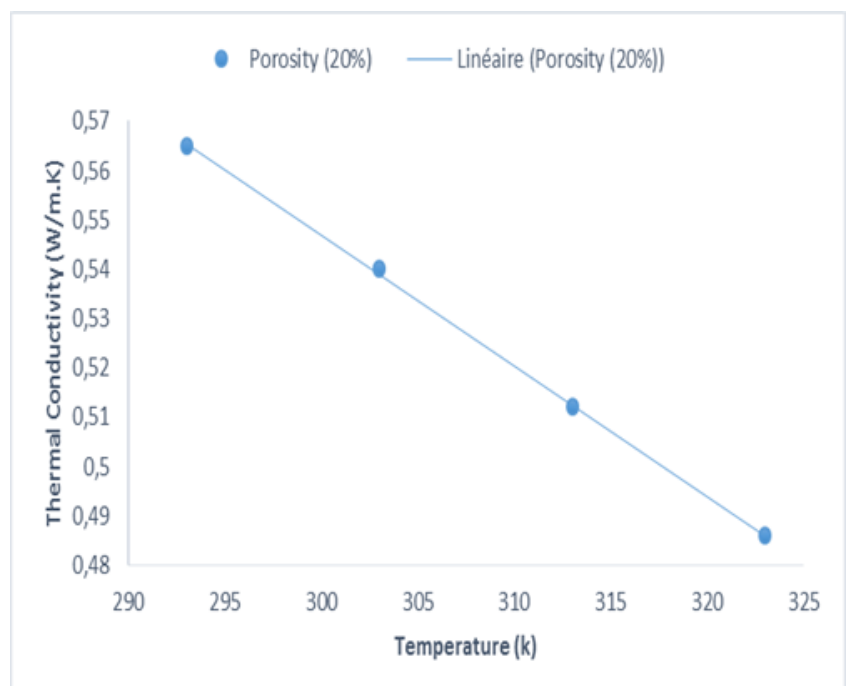

(e)

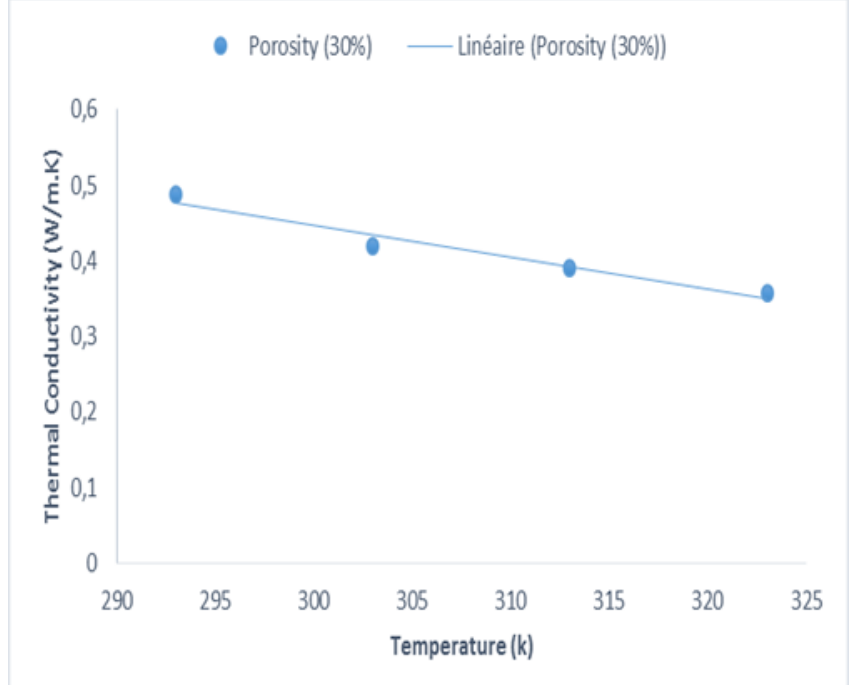

(f)

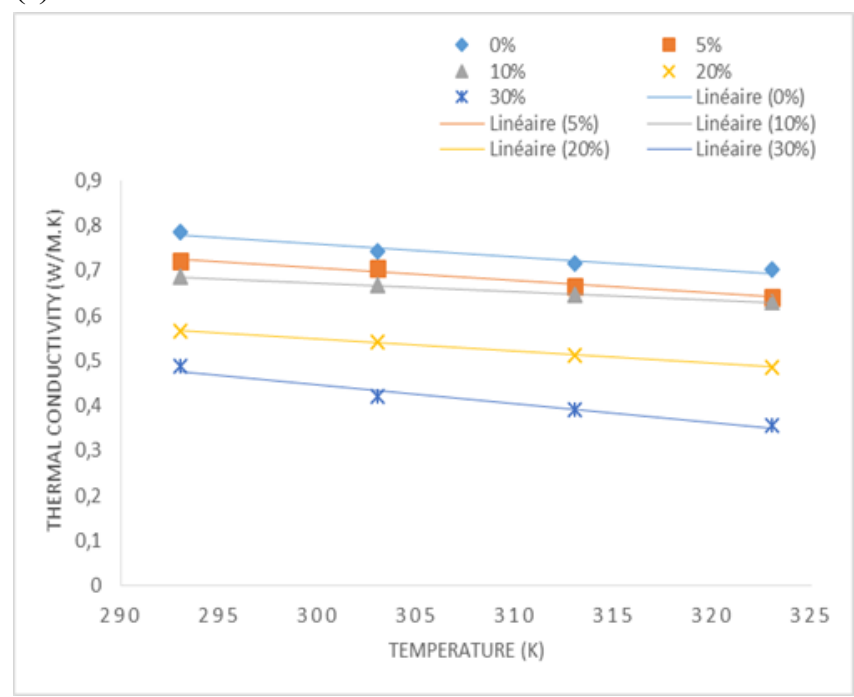

Figure 6. (a, b, c, d, e, f) Influence of thermal conductivity on temperature at different porosity values successively $(0 \%, 5 \%, 10 \%, 20 \%, 30 \%$ and all percentage of porosity) 
It is noted that the thermal conductivity decreases with the increase in temperature for all the samples but this very remarkable decrease when the porosity increases for example the thermal conductivity is $0.785 \mathrm{~W} \cdot \mathrm{m}^{-1} \mathrm{~K}^{-1}$ at temperature $\mathrm{T}=293 \mathrm{~K}$ for the $0 \%$ sample its value decreases with increasing temperature and reaches $0.701 \mathrm{~W} \cdot \mathrm{m}^{-1} \mathrm{~K}^{-1}$ at temperature $\mathrm{T}=323 \mathrm{~K}$, when the value of porosity is increased to $5 \%$ la thermal conductivity decreases further is becomes $0.721 \mathrm{~W} \cdot \mathrm{m}^{-1} \mathrm{~K}^{-1}$ at temperature $\mathrm{T}=293 \mathrm{~K}$ and decreases until it reaches 0.641 $\mathrm{W} \cdot \mathrm{m}^{-1} \mathrm{~K}^{-1}$ at temperature $\mathrm{T}=323 \mathrm{~K}$ the decrease becomes more apparent the decrease in temperature and the increase in porosity temperature and becomes $0.357 \mathrm{~W} \cdot \mathrm{m}^{-1} \mathrm{~K}^{-1}$ at temperature $\mathrm{T}=323$ $\mathrm{K}$ for the sample of $30 \%$. We can interpret these results by that the increase in temperature damages the crystal lattices of solid clay that is to say the solid becomes bad electrical conductor by consequence bad thermal conductor therefore the increase in temperature leads to a decrease in thermal conductivity.

\section{Conclusion}

The decrease in thermal conductivity with porosity, is aggravated with the increase in porosity that is to say the amount of air and the air has a mass and gases in general its viscosity decreases with the increase in temperature the viscosity decreases means that the interactions between weak particles which leads to a decrease in thermal conductivity.

The decrease in thermal conductivity as a function of temperature its origin at the interference of air atoms with the anionic sites of clay which end up at imperfect touches therefore a decrease in the efficiency of thermal waves, therefore decrease in thermal conductivity with increasing temperature.

In the field of clay construction, the porosity of the sample must be taken into account, which plays an important role in protecting people against temperature and cold.

\section{Nomenclature}

\section{$\lambda \quad$ Thermal conductivity $\left(W \cdot m^{-1} K^{-1}\right)$ \\ T Temperature $(K)$ \\ $\boldsymbol{x}_{\text {air }}$ Porosity (\%)}

CT-Metre: Device in Laboratory of Thermodynamic - Energy, Energy Center, Faculty of Sciences, Mohammed V University, Rabat, Morocco.

\section{Acknowledgment}

As authors we would like to thank you very much the Associate Editor for his support and assistance with the review of the paper and Team Thermodynamic- Energy, Energy center, Faculty of Sciences, Mohammed V University.

\section{References:}

[1] Samaouali A, El Rhaffari Y, Hraita M, Laanab L, Oudrhiri H, Géraud Y, Porous Network Structure and Total Porosity of Rocks Used in Historical Monument Challah (Rabat), Romanian Journal of Materials, 2017, 47 (2), 222 -229.

[2] Song-Nam Hong, Chol-Jun Yu, Un-Song Hwang, Chung-Hyok Kim, Byong-Hyok Ri. Effect of porosity and temperature on thermal conductivity of jennite: A molecular dynamics study, Materials Chemistry and Physics, Volume 250, 1 August 2020, 123146.

[3] A. Moufakkir, A. Samaouali, A. Elbouzidi, S. Elalami, A. Dinane, Thermophysical characterization of composite clay Materials doped by the copper powder according to the Temperature, WSEAS Transactions on Environment and Development, Volume 16, 2020, pp. 324-329.

[4] A. Moufakkir, A. Elbouzidi, A. Samaouali, Curves Characteristic of Natural Drying of Five Species of Wood. Advanced Studies in Theoretical Physics, Vol. 13, 2019, no. 2, $55-66$.

[5] Francisco Armijo, Francisco Maraver, Manuel Pozo, María Isabel Carretero, Onica Armijo, Miguel ÁngelFernández-Torán, María Virginia Fernández-González, IluminadaCorvillo. Thermal behaviour of clays and clay-water mixtures for pelotherapy, Applied Clay Science, Volume 126, June 2016, Pages 50-56.

[6] Lamine Zerbo, Brahima sorgho, Sié Kam, Julien Soro, Younoussa Millogo, BoubiéGuel, Karfa Traoré, Moussa Gomina, Philippe Blanchart, Comportement thermique de céramiques à base d'argiles naturelles du Burkina Faso, Journal de la 
Société Ouest-Africaine de Chimie, 17ème Année, Décembre 2012, № 034, pages 4856.

[7] Carlos Armenta-Deu, Leticia Bottazzi, VARIATION OF THERMAL CONDUCTIVITY WITH POROSITY, Journal of Geotechnical Engineering, vol 7, No 1 (2020).

[8] A Boulanouar, A Rahmouni, M Boukalouch, A Samaouali, Y Géraud, MimounHarnafi, Jamal Sebbani, Determination of Thermal Conductivity and Porosity of Building Stone from Ultrasonic Velocity Measurements, Geomaterials, 2013, 3, 138-144.

[9] Fatemeh Pashaei Soorbaghi, Mehrdad Kokabi, Ahmad Reza Bahramian, Predicting the effective thermal conductivity of silica/clay mineral nanocomposite aerogels, International Journal of Heat and Mass Transfer, Volume 136, June 2019, Pages 899-910.

[10] Y. EL Rhaffari, A.Samaouali, L. Laânab, Y. Geraud, M. Boukalouch, Conductivity and thermal diffusivity of the Chellah monument stones, 3rd International Meeting on the Architectural Heritage of the Mediterranean (RIPAM_3) ,15 - 17 October, 2009 Lusíada University Lisbon, Portugal.

[11] J.M. Molina, R. Prieto, J. Narciso, E. Louis. The effect of porosity on the thermal conductivity of $\mathrm{Al}-12$ wt. $\% \mathrm{Si} / \mathrm{SiC}$ composites, Scripta Materialia, Volume 60, Issue 7, April 2009, Pages 582-585.

[12] Rohit Malik, Young-Wook Kim, In-Hyuck Song. High interfacial thermal resistance induced low thermal conductivity in porous $\mathrm{SiC}-\mathrm{SiO} 2$ composites with hierarchical porosity, Journal of the European Ceramic Society, Volume 40, Issue 3, March 2020, Pages 594-602.

[13] Xavier Guillot, Muzahim Al-Mukhtar, Faiza Bergaya, Jean-Marie Fleureau. Estimation de la porosité dans un matériau argileux Porosity assessments in a clay material, Comptes Rendus Geoscience, Volume 334, Issue 2, 2002, Pages 105-109.

[14] Abdel R. Moustafa, Ralph B. Dinwiddie, Alexander E. Pawlowski, Derek A. Splitter, Amit Shyam, Zachary C. Cordero, Mesostructured and porosity effects on the thermal conductivity of additively manufactured interpenetrating phase composites, Additive Manufacturing, Volume 22, August 2018, Pages 223-229.

[15] Yinkang Zhou, Changhong Yan, Anh Minh Tang, Chenglong Duan, Shengshi Dong. Mesoscopic prediction on the effective thermal conductivity of unsaturated clayey soils with double porosity system, International Journal of Heat and Mass Transfer, Volume 130, March 2019, Pages 747-756.

[16] Imen Jmal, Mounir Baccar Numerical Study of Thermal Performances of a PCM-AIR Solar Heat Exchanger WSEAS Transactions on Fluid Mechanics, Volume 13, 2018, pp. 10-17

[17] Rajesh Sharma, Boundary Layer Slip Flow and Heat Transfer over an Exponential Shrinking Sheet WSEAS Transactions on Fluid Mechanics, Volume 13, 2018, pp. 18-25

[18] Alexander Blokhin, Ekaterina Kruglova, Boris Semisalov, Numerical Analysis of the Non-Isothermal Flow of Polymeric Liquid between Two Coaxial Cylinders WSEAS Transactions on Fluid Mechanics, Volume 13, 2018, pp. 26-36

\section{Creative Commons Attribution \\ License 4.0 (Attribution 4.0 \\ International , CC BY 4.0)}

This article is published under the terms of the Creative Commons Attribution License 4.0

https://creativecommons.org/licenses/by/4.0/deed.en US 